\title{
GPS 测绘技术在测绘工程中的应用
}

张更垒

山东省煤田地质局物探测量队

DOI:10.32629/gmsm.v3i1.553

[ 摘 要] 随着社会经济的高速发展, 各项工程建设项目层出不穷, 想要保证工程项目的建设质量,先要做好工程项目的测绘工程,建设单位需要 重视其测绘工程, 尽量避免出现技术差错, 进行精准的技术测绘。目前, 我国技术测绘工程中的GPS技术,广泛应用在各大测绘项目中,该技术比传 统的技术更加科学精准,但是GPS技术在实际的应用中, 也存在诸多不足之处,一定程度上对测绘工程质量造成影响。

[关键词] GPS; 测绘技术; 测绘工程; 应用

\section{GPS 技术原理}

就GPS而言, 以空间位置布置为依据可划分为卫星轨道、地面接收控制 点及用户信号接收装置等三个不同层次。一个完整的系统是由数量一定的 卫星组成的, 可全面化实现用户测量区域的覆盖, 用户将测量需求提出后, 地面接收控制点会将发射自空间卫星的定位导航信号接收, 用户仅需将 GPS接收终端设备打开便能实现所需位置信息的获取。就位置测量、导航 定位等各类需求而言, 通过此类方式的运用可实现有效满足。定位是GPS 技术的核心, 以各类定位方式为根据, 可划分为两种定位, 即相对与绝对定 位, 这两类定位都有着极高的测量精度。各类定位方式有着不一致的应用, 具备的特点也有显著差异。以几何空间理论为核心的相对定位, 需在明确 三个卫星距离及测量目标的基础上, 结合数学知识理论对测量位置信息进 行推断; 绝对定位则是以海拔、经纬度等信息为根据对测量位置的空间坐 标进行明确。

\section{GPS 测绘技术在测绘工程中应用的重要作用}

2. 1 保证数据精准性

在GPS测绘技术应用在测绘工程当中, 无论是动态化的测绘工作还 是静态化的测绘工作, 都能够保证数据信息的精准性, 能够将精准度控 制在有效范围内。GPS测绘技术通常情况下会由三部分构成, 分别是空 间、用户设备与地面控制。GPS测绘技术可以将自身精准性这一特点进 行充分发挥, 构建出相应的三维立体坐标, 收集到相应的数据信息。除此 之外, 还可以利用GPS测绘技术进行具有针对性的测绘工作, 这样可以更 好实现测绘目标。

\section{2 提升工作效率}

GPS测绘技术相较于传统的测绘技术而言, GPS测绘技术可以提升工作 人员的工作效率。因为在将GPS测绘技术应用在测绘工程当中, 可以在一次 的测量当中, 对不同的位置进行定位, 不需要反复测量定位。因为传统测量 工具与测量技术具有一定局限性, 每一只可以定位一个位置, 为工作人员 的测绘工作与定位工作带来难度。而GPS测绘技术的应用, 可以对传统测绘 工具当中存在的不足进行弥补, 减少工作量, 提升工作效率。

\section{GPS 测绘技术在测绘工程中的具体应用}

3.1 GPS外业测绘

测绘工程一般都是在户外的, 要进行在外作业。心要找到准确测量点, 直接关系到结果质量, 必须非常重视。选择测量点是要综合考察, 包括地质 条件、地形地貌、水文条件等, 这些都是很重要的。确定观测点位置, 要从 多个方位观察, 对仪器设备固定, 一定程度上提高了测量的准确性。测量出 现失误的原因是人员对区域情况不了解, 测量点和观测点选择不合理, 受
到人为主观因素影响较大, 凭借自身经验做出判断。要树立起全局意识, 从整体上把控, 了解测绘工程基本情况, 更好的开展测量, 保证数据信息科 学性, 符合后期建设的要求。

\subsection{GPS布网}

首先要合理规划、全面布网。人员到现场去勘查, 了解工程规模、面 积、用途等方面, 在此基础上进行布网。如果人员不负责, 会因为疏忽出现 漏洞, 降低了工作水平。其次坚持具体问题具体分析原则。因为每个地区 情况是不一样的, 不能采用单一方式, 要根据工程条件来判断, 选择合理的 实施方案。最后重视检查工作, 及时发现问题并解决, 消除其中存在隐患, 减少不利因素影响。GPS布网是一项重要工作, 树立起求真务实的态度, 尤 其是细节方面, 一定要处理好, 否则会影响到整体测量效果。工作人员除了 具备较强专业素养外, 还要增强责任意识, 对测量过程全面监控, 将工程质 量放在第一位, 确保没有任何问题。

3. 3 实时动态测绘法

又被称之为RTK, 工作原理是在地面上已有的测量点安装一个GPS接收 机, 作为测量点的基本准确点, 然后将其和GPS卫星连接, 接受测量信息, 传 输到中心测量站和测量流动站。其中流动测量站除了要接受GPS卫星型号 外, 还要接受其他设备的信息, 对所有数据整合处理。利用GPS导航的原理, 进行观察对比和分析数据, 借助计算机获得流动站的具体位置, 实时回传 这些信息, 就是我们所说的实时动态测绘法。不同部门人员之间要加强联 系, 保证信息传递、共享, 提高默契配合度。实时动态测绘始终处于监控之 中, 了解区域相关情况, 便于人员做出改变和调整, 达到更好的效果。结合 实际工作情况, 采用科学方法进行实施, 确保收集到最全面信息, 为工程建 设提供支持。

\section{4 结语}

GPS测量技术的应用解决了很多工程测绘的难题, 在未来的测绘工作 中, GPS测量技术必将得到更加广泛的引用, 同时其自身也会不断的进行技 术创新, 以适应市场经济的快速发展, 以为工程建设节约资源、降低成本、 提高质量, 并为国家和人民带来更大的经济效益和社会效益。

\section{[参考文献]}

[1]孙义仁.GPS测绘技术在测绘工程中的应用研究 [J].数字通信世 界,2019,(4):59.

[2]李爱国.GPS测绘技术在测绘工程中的应用研究 [J].科技创新导 报,2019,16(4):173.

[3]毛红涛.浅谈GPS测绘在工程测绘技术中的应用 [J].中国科技投 资,2018,(18):37. 